\title{
Ferimentos não fatais por arma de fogo entre policiais militares do Rio de Janeiro: a saúde como campo de emergência contra a naturalização da violência
}

\author{
Non-fatal gunshot wounds among military police in Rio de Janeiro: \\ health as a field of emergency against the naturalization of violence
}

Adriane Batista Pires Maia (https://orcid.org/0000-0001-6081-707X) ${ }^{1}$

Simone Gonçalves Assis (http://orcid.org/0000-0001-5460-6153) ${ }^{1}$

Fernanda Mendes Lages Ribeiro (https://orcid.org/0000-0002-3766-9758) ${ }^{1}$

Liana Wernersbach (https://orcid.org/0000-0003-1928-9265) ${ }^{1}$
${ }^{1}$ Departamento Estudos de Violência e Saúde Jorge Careli, Escola Nacional de Saúde Pública Sergio Arouca, Fundação Oswaldo Cruz. Rua Leopoldo Bulhões 1480, Manguinhos. 21041210 Rio de Janeiro RJ Brasil. adrianepmaia@gmail.com

\begin{abstract}
This article discusses health problems due to firearm injuries suffered on duty military police officers in the metropolitan region of Rio de Janeiro (RJ). Medical records analysis was con ducted referring to military police officers who were treated at the Military Police's Central Hos pital (MPCH) due to gunshot wounds from June 2015 to December 2017 according to professional profile, the characteristics of the event and the le sion, the spatial distribution of the incidents in volving gunshot wounds, and the healthcare units involved in their care. Firearms injured four hun dred seventy-five military police officers: $98.3 \%$ were male, $77.3 \%$ were in service, 97.9\% were soldier personnel. As to the anatomical location of the wounds, the most affected regions were: lower (41.1\%) and superior (33.1\%) limbs, the head neck-face region (23.5\%), and thorax-abdomen (3\%). The areas in the metropolitan area of Rio de Janeiro with the highest occurrence of firearm morbidity are program areas 3 and 1 and the Baixada Fluminense. There is a correlation between police morbidity rates due to firearm injuries in the municipalities of the metropolitan region and demographic density $(p=0.024)$.
\end{abstract}

Key words Morbity, Police, Public safety, Gunshot wound, Occupational health
Resumo Esse artigo aborda a ocorrência de agravos à saúde decorrentes de ferimentos por arma de fogo (FAF) que atingiram policiais militares da ativa na Região Metropolitana do Rio de Janeiro (RJ). Pesquisa documental, por meio de análise de prontuários médicos de policiais militares atendidos no Hospital Central da Polícia Militar (HCPM) em decorrência de FAF, no período de junho de 2015 a dezembro de 2017 segundo variáveis relativas ao perfil profissional, às características do evento e da lesão, à distribuição espacial dos FAF $e$ às unidades de saúde envolvidas no atendimento. No período investigado, 475 policiais militares sofreram ferimentos por armas de fogo: $98,3 \%$ do sexo masculino, $77,3 \%$ encontravam-se em serviço, 97,9\% eram praças. Quanto à localização anatômica dos ferimentos, as regiões mais acometidas foram: membros inferiores $(41,1 \%)$ e superiores (33,1\%), região da cabeça-pescoço-face $(23,5 \%) e$ tórax-abdome (17,3\%). As áreas na Região Metropolitana do Rio de Janeiro onde foram encontradas as maiores ocorrências de morbidade por arma de fogo foram as áreas de planejamento $3 e$ 1 e a Baixada Fluminense. Constatou-se correlação entre as taxas de morbidade policial por armas de fogo dos municípios da região metropolitana e densidade demográfica $(p=0,024)$.

Palavra-chave Morbidade, Polícia, Segurança pública, Ferimentos por arma de fogo, Saúde ocupacional 


\section{Introdução}

O Brasil é um país marcado pela violência, no entanto, no imaginário social, existe o mito de que somos um país pacífico ${ }^{1}$. Nos últimos 35 anos, apesar da retomada dos direitos civis e do restabelecimento do estado democrático de direitos, indicadores de violência social permanecem elevados e até mesmo crescentes, a reboque da globalização e da urbanização. A despeito de não vivermos conflitos armados de cunho religioso, étnico, territorial ou político, entre 1980 e 2014 morreram 967.851 pessoas em virtude de ferimentos por arma de fogo (FAF), o que nos coloca entre os 10 países com maior taxa de homicídio por arma de fogo no mundo. Entre as vítimas fatais, constata-se perfil majoritário de homens entre 15 e 29 anos de idade e negros. A vitimização por arma de fogo entre a população negra é 2,6 vezes maior que entre os brancos ${ }^{2-4}$. Phebo $^{5}$ concluiu que entre as mortes por causas externas, aquelas causadas por arma de fogo ultrapassaram as ocorridas por acidentes de trânsito, tornandose a primeira causa entre os homicídios, o que gera impacto no custo das hospitalizações na rede credenciada do Sistema Único de Saúde (SUS).

Esse tipo de violência social também tem atingido os policiais militares no país. O Rio de Janeiro foi o estado que apresentou o maior número absoluto de policiais militares mortos em $2016^{6}$, contudo não são conhecidos os números das morbidades por armas de fogo entre essa classe de trabalhadores, o que dificulta a compreensão da real magnitude desse problema. Ehikhamenor e $\mathrm{Ojo}^{7}$ concluíram que as características dos ferimentos entre profissionais de segurança diferem das características encontradas na prática civil, tanto do ponto de vista epidemiológico quanto nos caminhos para o seu tratamento.

Em pesquisa de revisão sistemática sobre profissionais de segurança pública acometidos por ferimentos com arma de fogo, constata-se que este objeto letal foi o principal mecanismo de ferimento em serviço entre os policiais, mais frequente entre profissionais de segurança do sexo masculino, com cerca de 31 anos de idade. As circunstâncias de maior risco foram: ações de prisão, em respostas a demandas para verificação de perturbação à ordem e situações de guerra ${ }^{8}$.

No Brasil, a escalada da ocorrência desse tipo de ferimento se dá em virtude da penetração ilegal de armas com elevado potencial de destruição, o que afeta não só a população civil como também os profissionais de segurança pública, tornando-se um problema de saúde pública ${ }^{2}$. A despeito disso, poucos estudos têm buscado investigar e descrever a localização desses ferimentos e os impactos na saúde do policial tanto para o desempenho profissional quanto em sua vida social ${ }^{1,9}$. Isso se deve ao fato de que, no Brasil, não há um sistema nacional integrado que registre a morbimortalidade dos agentes de segurança pública ${ }^{9-11}$.

Atualmente, os relatórios sobre a mortalidade entre os profissionais de segurança pública no Brasil, quando existem, são fragmentados e incompletos, e reune dados fornecidos por alguns Institutos de Segurança ou Secretarias Estaduais de Segurança Pública. no Estado do Rio de Janeiro, o último Relatório de Vitimização Policial foi publicado em 2015, e não abordava, contudo, as morbidades produzidas por arma de fogo entre esses profissionais ${ }^{12}$.

$\mathrm{O}$ atendimento em saúde dos policiais militares no Rio de Janeiro possui particularidades que os diferem dos demais usuários do SUS, já que contam com a possibilidade de adesão a um plano de saúde coorporativo custeado por recursos financeiros captados a partir de contribuição voluntária dos policiais ativos e inativos, seus dependentes e pensionistas, que viabilizam o funcionamento do Sistema de Saúde da Corporação. O Hospital Central da Polícia Militar (HCPM) é, atualmente, o hospital de referência para atendimento de urgências e emergências dos policiais militares e seus dependentes no estado do Rio de Janeiro.

Dessa forma, esse estudo tem como objetivo identificar o perfil e o atendimento em saúde dos policiais militares do estado do Rio de Janeiro acometidos por ferimentos não fatais por arma de fogo atendidos no Hospital Central da Polícia Militar.

\section{Método}

Efetuou-se um levantamento referente aos policiais militares que foram atendidos no HCPM em decorrência de FAF, definidos como qualquer tipo de lesão física não fatal por arma de fogo, independente da gravidade da lesão provocada. Descrevese a frequência e a distribuição das agressões por arma de fogo no universo dos policiais da Região Metropolitana do Rio de Janeiro que não faleceram imediatamente em decorrência do ferimento e que foram levados para o referido hospital.

A busca foi realizada nos Relatórios de Policiais Atendidos por Ferimento com Arma de Fogo do HCPM, abrangendo de junho de 2015 a dezembro de 2017. A coleta foi feita no Setor de 
Pronto Atendimento (SPA) do HCPM, que registra, desde 2014, informações sobre todo policial atendido com FAF. Foi excluído o período de julho de 2014 a maio de 2015 em virtude da falta de arquivamento adequado dos registros, que gerou a perda dos dados. As informações dos prontuários e Relatórios foram acessadas em 2018. Os registros dos prontuários médicos são gerados a partir do Boletim de Entrada do paciente no SPA, já os Relatórios são alimentados inicialmente pelo oficial de dia, médico militar responsável pela emergência, que lança em brochura as informações referentes a cada militar ferido por projéteis de armas de fogo. Essa brochura é encaminhada a cada dois dias à secretaria do HCPM, onde um policial militar lotado na secretaria transcreve as informações da brochura para uma ficha denominada Relatório de Policiais Atendidos por Projétil com Arma de Fogo. Após o preenchimento, a ficha de notificação é arquivada na secretaria no formato impresso, jamais digitalizada.

Foram analisadas variáveis referentes a: a) perfil dos profissionais: sexo, posto/graduação do policial e batalhão de lotação; b) características dos eventos e das lesões: data e local da ocorrência, FAF ocorrido em serviço ou em folga, localização anatômica, classificação do estado de saúde do paciente em bom, regular ou grave, tempo de internação hospitalar, se foi a óbito ou não durante a internação, revitimização (sim ou não) e número de cirurgias realizadas em caráter de urgência no HCPM em decorrência do ferimento; c) distribuição geográfica dos FAF: local do evento na cidade do Rio de Janeiro, segundo Áreas Planejamento (APs); para a região da Baixada Fluminense, Niterói e São Gonçalo, considerouse o distrito envolvido; e d) distribuição espacial das unidades de saúde envolvidas no atendimento: informações sobre os hospitais envolvidos no atendimento primário dos policiais militares baleados e identificação da Região Metropolitana do Rio de Janeiro onde estes se localizavam.

Os dados coletados foram inseridos no programa Epidata 3.1 e exportados para o programa SPSS 20.0, no qual foram elaboradas distribuições de frequências simples, relativas e bivariadas para variáveis selecionadas.

Com a finalidade de analisar a distribuição temporal dos eventos, organizou-se os dados segundo mês/ano de ocorrência, e construiu-se gráfico para apresentar a série temporal e calculada a variação percentual entre os meses/anos.

Com a finalidade de identificar alguns fatores associados à vitimização policial por arma de fogo, calculou-se a taxa de morbidade policial por arma de fogo usando-se como numerador o quantitativo de policiais feridos (por município e, no caso do município do Rio de Janeiro, também por área de planejamento) e como denominador a população de policiais da referida área. Como variáveis explicativas empregaram-se o Índice de Desenvolvimento Humano Municipal (IDHM) ${ }^{13}$, o percentual da população vivendo em aglomerados subnormais ${ }^{14}$ e a densidade demográfica das áreas ${ }^{14}$. Para esta análise empregou-se o coeficiente de correlação de Pearson.

A pesquisa foi submetida e aprovada pelo Comitê de Ética em Pesquisa da Escola Nacional de Saúde Pública Sergio Arouca / Fiocruz.

\section{Resultados}

Foram incluídos 475 registros de policiais militares da ativa atendidos no SPA do HCPM em decorrência de FAF. Quanto ao perfil dos policiais militares da ativa atendidos, $98,3 \%$ são do sexo masculino, com 8 casos de mulheres policiais com ferimentos por armas de fogo. Ao realizar a distribuição temporal dos indivíduos que sofreram FAF observou-se que, entre junho e dezembro de 2015, foram encontradas 78 ocorrências; no ano de 2016 ocorreram 172 ocorrências; e em 2017 houve um aumento desse tipo de violência, atingindo 222 atendimentos. Não se observou diferença substancial entre os meses do ano. Houve um crescimento desse tipo de morbidade entre julho de 2015 e dezembro de 2017 (Tabela 1).

Entre os 470 casos analisados, em apenas 5 não foi possível identificar se o policial encontrava-se em serviço ou em folga no momento do ferimento, logo estes excluídos da análise. Vimos que, entre os 470 casos analisados, parte significativa dos atendimentos efetuados ocorreu em serviço (77,2\%, equivalente 3 para 63 casos), decorrentes da atividade laboral através do exercício do policiamento ostensivo e de operações policiais com confronto armado na cidade (349) e de disparos acidentais (14). Em 107 casos, os policiais militares foram baleados durante o período de folga.

Quanto à distribuição dos policiais por patentes, entre os 472 feridos, 251 são soldados (53,3\%). Notou-se que, à medida que a patente avança na hierarquia institucional, menor é a frequência de FAF. Foi encontrado entre os praças (categoria que inclui de soldados a segundo-tenentes) a quase totalidade dos atendimentos, com 97,9\% das ocorrências (Tabela 2). Verifica-se a relação de 46 praças para cada um oficial acome- 
Tabela 1. Evolução temporal dos ferimentos por arma de fogo ocorridos entre policiais militares da Região Metropolitana do Rio de Janeiro - junho de 2015 a dezembro de $2017(\mathrm{~N}=472)$

\begin{tabular}{lrrrrr}
\hline \multirow{1}{*}{ Mês } & & Ano & & $\begin{array}{c}\text { D\% } \\
\mathbf{1 5 - 1 6}\end{array}$ & $\begin{array}{c}\text { D\% } \\
\mathbf{1 6} \text {-17 }\end{array}$ \\
\cline { 2 - 6 } & $\mathbf{2 0 1 5}$ & $\mathbf{2 0 1 6}$ & $\mathbf{2 0 1 7}$ & & \\
\hline Janeiro & $*$ & 14 & 18 & $*$ & 28,57 \\
Fevereiro & $*$ & 16 & 27 & $*$ & 68,75 \\
Março & $*$ & 14 & 17 & $*$ & 21,43 \\
Abril & $*$ & 21 & 19 & $*$ & $-9,52$ \\
Maio & $*$ & 16 & 26 & $*$ & 62,50 \\
Junho & 12 & 20 & 24 & 66,67 & 20,00 \\
Julho & 11 & 9 & 14 & $-18,18$ & 55,56 \\
Agosto & 4 & 14 & 9 & 250,00 & $-35,71$ \\
Setembro & 13 & 11 & 20 & $-15,38$ & 81,82 \\
Outubro & 9 & 13 & 16 & 44,44 & 23,08 \\
Novembro & 19 & 12 & 12 & $-36,84$ & 0,00 \\
Dezembro & 10 & 12 & 20 & 20,00 & 66,67 \\
Total & 78 & 172 & 222 & 120,51 & 29,07 \\
& & D \% & & 44,39 & 31,93 \\
& & média & & & \\
\hline
\end{tabular}

* Dados não disponíveis.

Fonte: Registros do Hospital Central da PMRJ levantados para a pesquisa. tidos por ferimento por arma de fogo na Região Metropolitana do Rio de Janeiro.

Em relação à origem/localização dos Batalhões de Polícia Militar (BPM) nos quais trabalhavam os policiais feridos por arma de fogo, encontramos maior ocorrência de lotações nas unidades que desenvolvem a atividade-fim da PMERJ (438 policiais feridos), em comparação às unidades administrativas (37 feridos). Entre aqueles lotados nas Unidades de Polícia Pacificadoras (UPPs), foram encontrados mais feridos em números absolutos: $16^{\circ}$ BPM UPP (49 feridos), $3^{\circ}$ BPM UPP (33 feridos), ambos na Área de Planejamento (AP) 3; o 4 ${ }^{\circ}$ BPM UPP na AP 1 (34 feridos); seguem em frequência policiais que trabalham no Batalhão de Operações Especiais - BOPE (32), ressaltando-se que o BOPE atua em todas as áreas do Rio de Janeiro. Contudo, se compararmos o número de feridos por armas de fogo segundo o total de policiais militares em cada batalhão, vemos que, proporcionalmente, o BOPE foi o batalhão com a maior proporção de policiais baleados $(6,6 \%)$, seguido pelo $18^{\circ}$ BPM UPP, localizado na Cidade de Deus (AP 4) $(4,6 \%)$. Os demais batalhões oscilam entre $1 \%$ e $3,5 \%$ de profissionais feridos por armas de fogo.

Tabela 2. Distribuição do quantitativo de policiais militares da Região Metropolitana do Rio de Janeiro feridos por armas de fogo, segundo patente.

\begin{tabular}{lcccc}
\hline \multicolumn{1}{c}{ Patentes } & $\begin{array}{c}\text { Número de PMs da } \\
\text { ativa }^{*}\end{array}$ & $\begin{array}{c}\text { \% de PMs/RJ } \\
\text { segundo patentes }\end{array}$ & $\begin{array}{c}\text { Frequência de } \\
\text { baleados }\end{array}$ & $\begin{array}{c}\text { \% de baleados } \\
\text { segundo patentes }\end{array}$ \\
\hline Oficiais & 105 & 0,2 & - & - \\
Coronel & 344 & 0,8 & - & - \\
Tenente-coronel & 836 & 1,9 & 2 & 0,4 \\
Major & 1.050 & 2,3 & 3 & 0,6 \\
Capitão & 790 & 1,8 & 4 & 0,2 \\
10 Tenente & 222 & 0,5 & 1 & 2,1 \\
2o Tenente & 3.347 & 7,5 & 10 & - \\
Subtotal & & & & 4,0 \\
Praças & 70 & 0,16 & - & 2,8 \\
Aspirante / Cadete & 4.484 & 10,1 & 19 & 11,2 \\
Subtenente & 2.420 & 5,4 & 13 & 10,3 \\
1o Sargento & 8.011 & 18,0 & 53 & 16,3 \\
2o Sargento & 5.040 & 11,3 & 49 & 53,3 \\
3o Sargento & 10.429 & 23,4 & 77 & 97,9 \\
Cabo & 10.737 & 24,1 & 251 & 100,0 \\
Soldado & 41.191 & 92,5 & 462 & \\
Subtotal & 44.538 & 100,0 & 472 & \\
Total de PM/RJ & & & & \\
\hline
\end{tabular}

${ }^{*}$ Proporção de feridos avaliados no artigo segundo quantidade de policiais militares na PMERJ.

Fonte: Departamento de Pessoal da Ativa/PMERJ - 2018. 
Entre os 475 pacientes atendidos no Setor do Pronto Atendimento do HCPM, 571 foram listados por FAF, distribuídos quanto a localização anatômica entre membros superiores e inferiores, cabeça-pescoço-face e tórax-abdome (Tabela 3), distribuídos em ordem decrescente das regiões acometidas: membros inferiores $(41,1 \%)$ e superiores $(33,1 \%)$, região da cabeça-pescoço-face $(23,5 \%)$ e tórax-abdome (17,3\%).

Quanto ao estado clínico dos policiais atendidos após acolhimento na emergência do HCPM, entre os 474 pacientes, 5,6\% foram classificados como grave, $90,9 \%$ em estado clínico regular e 3,5\% bom. Dos 466 atendimentos, 78 pacientes $(16,7 \%)$ precisaram ser operados em caráter de urgência no HCPM. Dentre os policias atendidos, 8 evoluíram a óbito durante a internação hospitalar (1,7\%). Três casos $(0,6 \%)$ de revitimização por arma de fogo ocorreram no período avaliado. Quanto ao tempo de internação hospitalar, constatou-se a mediana de 0,0 dias de internação hospitalar.

Para análise da distribuição espacial dos locais de ocorrência dos FAF, foi realizado um recorte dos 475 casos levantados, excluindo-se da amostra 4 casos que ocorreram fora da Região Metropolitana da cidade (Macaé e Cabo Frio), 26 casos em que não foi possível identificar a localização de ocorrência do FAF e 14 casos por tratarem de acidentes ocorridos dentro dos batalhões durante treinamento ou manipulação da arma de fogo com disparo acidental. Dessa forma, foram considerados 431 policiais militares: 349 na cidade do Rio de Janeiro, 70 nos distritos da Baixada

Tabela 3. Distribuição anatômica dos ferimentos por armas de fogo que atingiram policiais militares da Região Metropolitana do Rio de Janeiro ( $\mathrm{N}=475)$

\begin{tabular}{lcr}
\hline \multirow{2}{*}{$\begin{array}{c}\text { Distribuição anatômica } \\
\text { dos ferimentos por armas } \\
\text { de fogo }\end{array}$} & \multicolumn{2}{c}{ Sim } \\
\cline { 2 - 3 } & Frequência & \multicolumn{1}{c}{$\%$} \\
\hline Região de face & 51 & 10,7 \\
Região de cabeça & 49 & 10,3 \\
Região de pescoço & 12 & 2,5 \\
Região tórax e abdome & 82 & 17,3 \\
Região membros inferiores & 195 & 41,1 \\
Região membros superiores & 157 & 33,1 \\
Outras regiões & 25 & 5,3 \\
\hline * Alguns pacientes acometidos por FAF foram atingidos em \\
mais de uma parte do corpo. \\
Fonte: Registros do Hospital Central da PMRJ levantados para \\
a pesquisa.
\end{tabular}

Fluminense, 9 em Niterói e 3 em São Gonçalo. Em $51,2 \%$ dos casos, os tiroteios aconteceram em regiões de comunidade e durante incursões policiais.

Sobre os dados para o município do Rio de Janeiro e suas áreas de planejamento (AP), temse que a AP 3 (área mais povoada e com o maior percentual de aglomerados subnormais) foi a região com a maior frequência de morbidades por arma de fogo em números absolutos (190) e também com a maior taxa de morbidade policial por arma de fogo na cidade. Destacam-se especialmente os bairros da Penha (26 policiais feridos), Complexo do Alemão (23), Manguinhos (16), Maré (11), Lins de Vasconcelos (10), Jacarezinho (10), Barros Filho (6) e Méier (6). A AP 1, localizada na região central da cidade, ostenta a segunda maior frequência de policiais militares baleados não fatalmente na cidade do Rio de Janeiro (73), principalmente no Centro (16), Gamboa (15), Estácio (14) e Caju (7). Na AP 2 foram encontrados 44 casos de policiais militares baleados não fatalmente, 25 desses ocorridos em favelas, destacando-se Tijuca (14, sendo 9 em favelas), Copacabana ( 8 , todos na comunidade Pavão-Pavãozinho), Laranjeiras (6) e Vila Isabel (5). $\mathrm{Na}$ AP 4 foram encontrados 25 casos, com destaque para a alta frequência de baleados na Cidade de Deus (19). A AP 5 (maior em extensão territorial e menor em concentração de aglomerados subnormais) foi a região com a menor frequência de policiais baleados não fatalmente, com 17 casos, sendo Bangu (5) o bairro com maior percentual de ocorrências $(29,4 \%)$. Embora tenha se constatado alta correlação entre morbidade policial por FAF e população que vive em aglomerados subnormais no município do Rio de Janeiro, não se alcançou a significância estatística ( $\mathrm{p}=0,065)$.

Ao considerar os outros municípios da Região Metropolitana estudados, tem-se que na região da Baixada Fluminense foram encontrados 70 policiais militares baleados: São João de Meriti somou o maior número de casos (18), seguido por Duque de Caxias (17), Nova Iguaçu (10), Mesquita (6), Nilópolis (6), Belford Roxo (5), Magé (4), Itaguaí (2), Japeri (1) e Queimados (1). No município de Niterói foram registrados 9 casos de policiais militares baleados, seguido por São Gonçalo, com 3 casos. São João de Meriti apresentou a maior taxa de morbidade policial por arma de fogo enquanto que São Gonçalo a menor taxa (Tabela 4). Constatou-se correlação entre as taxas de morbidade policial por armas de fogo dos municípios da Região Metropolitana (exceto Rio de Janeiro) e densidade demográfica $(\mathrm{p}=0,024)$. 
Tabela 4. Distribuição espacial dos locais onde ocorreram os ferimentos de policiais por armas de fogo na Região Metropolitana do Rio de Janeiro.

\begin{tabular}{|c|c|c|c|c|c|c|c|}
\hline \multirow[t]{2}{*}{$\begin{array}{l}\text { Região Metropolitana RJ } \\
\text { \% da população da cidade e } \\
\text { número de bairros }\end{array}$} & \multicolumn{2}{|c|}{$\begin{array}{c}\text { Policiais } \\
\text { militares com } \\
\text { ferimentos } \\
\text { por armas de } \\
\text { fogo } \\
\end{array}$} & \multirow[t]{2}{*}{$\begin{array}{l}\text { População } \\
\text { de } \\
\text { policiais } \\
\text { militares }\end{array}$} & \multirow[t]{2}{*}{$\begin{array}{c}\text { Taxas de } \\
\text { morbidade } \\
\text { policial } \\
\text { por armas } \\
\text { de fogo }^{\star}\end{array}$} & \multirow[t]{2}{*}{$\begin{array}{c}\text { Densidade } \\
\text { demográfica } \\
\left(\mathbf{h a b} / \mathbf{k m}^{2}\right)\end{array}$} & \multirow[t]{2}{*}{$\begin{array}{c}\text { \% População } \\
\text { vivendo em } \\
\text { aglomerados } \\
\text { subnormais } \\
\star \star\end{array}$} & \multirow[t]{2}{*}{$\operatorname{IDH}^{\star * *}$} \\
\hline & $\mathbf{N}$ & $\%$ & & & & & \\
\hline Rio de Janeiro (126 bairros) & 349 & 81,0 & 24616 & 14,18 & $5.265,82$ & 22,2 & 0,80 \\
\hline $\begin{array}{l}\text { AP1/RJ ( } 4,6 \% \text { da população; } \\
15 \text { bairros) }\end{array}$ & 73 & 20,9 & 2902 & 25,16 & $8.664,61$ & 28,6 & 0,83 \\
\hline $\begin{array}{l}\text { AP2/RJ: } 2.1 \text { e } 2.2(17,0 \% \text { da } \\
\text { população; } 25 \text { bairros) }\end{array}$ & 44 & 12,6 & 4.123 & 10,67 & $10.048,49$ & 14,7 & 0,93 \\
\hline $\begin{array}{l}\text { AP3/RJ: } 3.1,3.2 \text { e } 3.3 \text { ( } 40,2 \% \\
\text { da população; } 80 \text { bairros) }\end{array}$ & 190 & 54,4 & 6.298 & 30,17 & $11.791,22$ & 23,1 & 0,83 \\
\hline $\begin{array}{l}\text { AP4/RJ ( } 11,6 \% \text { da } \\
\text { população; } 19 \text { bairros })\end{array}$ & 25 & 7,2 & 1.343 & 18,62 & $3.095,30$ & 21,2 & 0,84 \\
\hline $\begin{array}{l}\text { AP5/RJ: } 5.1,5.2 \text { e } 5.3 \text { ( } 26,6 \% \\
\text { da população; } 20 \text { bairros) }\end{array}$ & 17 & 4,9 & 1.581 & 10,75 & $2.877,50$ & 11,6 & 0,79 \\
\hline Niterói ( 52 bairros) & 9 & 2,1 & 978 & 9,20 & $3.640,80$ & 16,4 & 0,84 \\
\hline São Gonçalo (63 bairros) & 3 & 0,7 & 896 & 3,35 & $4.035,90$ & 1,3 & 0,74 \\
\hline $\begin{array}{l}\text { São João de Meriti ( } 13 \\
\text { bairros) }\end{array}$ & 18 & 4,2 & 439 & 41,00 & $13.024,56$ & 10,3 & 0,72 \\
\hline Duque de Caxias (30 bairros) & 17 & 3,9 & 1.006 & 16,90 & $1.828,51$ & 7,2 & 0,71 \\
\hline Nova Iguaçu (73 bairros) & 10 & 2,3 & - & - & $1.527,60$ & 1,2 & 0,71 \\
\hline Mesquita (17 bairros) & 6 & 1,4 & 903 & 24,36 & $4.310,48$ & 0,6 & 0,74 \\
\hline Nilópolis (15 bairros) & 6 & 1,4 & - & - & $8.117,62$ & 2,3 & 0,75 \\
\hline Belford Roxo (23 bairros) & 5 & 1,2 & 359 & 13,93 & $6.031,38$ & 7,6 & 0,68 \\
\hline Magé (31 bairros) & 4 & 0,9 & 361 & 11,08 & 585,13 & 8,2 & 0,71 \\
\hline Itaguaí (49 bairros) & 2 & 0,5 & - & - & 395,45 & 7,5 & 0,72 \\
\hline Japeri (51 bairros) & 1 & 0,2 & 477 & 8,39 & $1.166,37$ & 2,5 & 0,66 \\
\hline Queimados (60 bairros) & 1 & 0,2 & - & - & $1.822,60$ & 3,9 & 0,68 \\
\hline Total & 431 & 100,0 & - & - & - & - & - \\
\hline \multicolumn{8}{|c|}{$\begin{array}{l}\text { * Município do RJ - Taxas de morbidade policial por armas de fogo/densidade demográfica }\left(\mathrm{hab} / \mathrm{km}^{2}\right): \mathrm{r}=0.521 ; \mathrm{p}=0.368 . \\
\text { * Município do RJ - Taxas de morbidade policial por armas de fogo/\% População vivendo em aglomerados subnormais: } \mathrm{r}=0.855 \text {; }\end{array}$} \\
\hline
\end{tabular}

Fonte: Registros do Hospital Central da PMRJ levantados para a pesquisa.

Entre os hospitais que realizaram o primeiro atendimento dos policiais com FAF na Região Metropolitana da cidade, os pertencentes à rede do SUS representaram 58\% dos atendimentos, seguidos pelo HCPM, com 34,7\% dos atendimentos, as Unidades de Pronto Atendimento (4\%) e os hospitais particulares (3\%). Entre os hospitais da rede do SUS, as principais unidades de saúde utilizadas por feridos foram: Hospital Getúlio Vargas (68), Hospital Salgado Filho (25) e Hospital Carlos Chagas (21), todos localizados na área programática 3 de saúde da cidade. $\mathrm{O}$ HCPM, a despeito de estar situado na AP 1 da cidade, continuou o principal hospital no atendimento primário dos policiais militares, o que totalizou 35\% dos atendimentos. Importa ressaltar que os 475 pacientes incluídos nesta pesquisa foram atendidos no HCPM, seja de forma primária ou após transferência de outras unidades. 
O artigo aborda a ocorrência de agravos à saúde produzidos por ferimentos por arma de fogo (FAF) não fatais que atingiram policiais militares do estado do Rio de Janeiro (RJ) que atuavam na Região Metropolitana da cidade durante suas atividades de trabalho. Problematiza a falta de informação em saúde dessa classe trabalhadora e o papel das diretorias de saúde da corporação como campus de emergência frente ao discurso de naturalização da vitimização do policial militar.

$\mathrm{O}$ perfil dos militares acometidos por FAF encontrado neste artigo foi de praças, em especial soldados, majoritariamente do sexo masculino. Quanto ao ferimento, foram baleados em serviço, portanto, decorrentes de acidentes de trabalho. A PMERJ é uma instituição hierarquizada e organizada em subdivisões dentro de duas categorias: oficiais e praças. Os oficiais são preparados, ao longo de sua carreira, para exercer funções de comando, chefia e direção. Os praças, em especial os cabos e os soldados são, essencialmente, preparados para o policiamento ostensivo e para ações de execução. A maior ocorrência de morbidade por arma de fogo entre essa categoria pode ser explicada, em parte, pela maior exposição durante o policiamento ostensivo. Esse perfil assemelha-se ao encontrado por Plani, Bowley e Goosen ${ }^{12}$, em levantamento realizado entre os policiais na África do Sul.

Segundo o Departamento de Pessoal da Ativa da PMERJ, a instituição tem no seu quadro 44.561 policiais ativos no ano de 2018 , 9,5\% desses do sexo feminino. Considerando-se o percentual de $1,7 \%$ das policiais femininas feridas por armas de fogo, pode-se indagar se estão menos expostas ao perigo, por trabalhar em áreas administrativas ou em posições menos vulneráveis a agressões por armas de fogo.

Os números absolutos de policiais alvejados no período estudado demonstram o elevado risco de morbidade por arma de fogo entre os policiais militares do Rio de Janeiro, especialmente quando comparamos com outras cidades no mundo. O The Law Enforcement Officers Killed and Assaulted (FBI) nos Estados Unidos da América (EUA) registra rotineiramente todas as ocorrências de morbimortalidade entre os agentes de segurança do país. Em relatório publicado em 2017, num universo de 586.446 profissionais de segurança em todo país, foram notificados 282 casos de ferimentos por arma de fogo em todo o território estadunidense no ano de $2016^{16}$. Berman e Salter ${ }^{17}$, em artigo de levantamento sobre morbimortalidade por arma de fogo entre os policiais da Filadélfia (EUA), encontraram 125 policiais que foram baleados não fatalmente em 12 anos de análise. Plani, Browley e Goosen ${ }^{15}$, na África do Sul, identificaram em 9 anos de levantamento 92 policiais feridos por armas de fogo. No Brasil, apenas Muniz e Soares ${ }^{18}$, Souza e Minayo $^{19}$ e Minayo et al. ${ }^{20-22}$ publicaram dados de morbidade entre policiais militares no RJ, sem, contudo, dar ênfase nas morbidades produzidas por armas de fogo.

A principal circunstância envolvida na ocorrência de morbidade por armas de fogo entre os policiais militares decorreu de dinâmicas conflituosas em comunidades na cidade do Rio de Janeiro, assim como foi encontrado por Muniz e Soares ${ }^{18}$, diferenciando-se de outras cidades no mundo em que as chamadas de resposta ao distúrbio da ordem e tentativa de prisão representam as circunstâncias de maior risco para os policiais $^{16,17,23}$.

Nas áreas urbanas do município do Rio de Janeiro com o maior percentual de conglomerados subnormais, AP1 e AP3, foi encontrada alta concentração de morbidade policial por arma de fogo, entretanto, ao considerarmos as taxas de morbidade policial por armas de fogo e o percentual da população que vivem em aglomerados subnormais $(\mathrm{r}=0,855 ; \mathrm{p}=0,065)$, esse resultado não é significativo. Da mesma forma, se considerarmos as taxas de morbidade policial por arma de fogo e o Índice de Desenvolvimento Humano no município do RJ, não encontramos uma associação significativa entre esses fatores $(r=-0,309$; $\mathrm{p}=0,612$ ), diferente do observado por Kyriacou et al. ${ }^{24}$ ao analisar as causas das mortes dos policiais nas cidades de Nova Iorque e Londres durante o século XX.

Sobre a maior ocorrência desse tipo de morbidade nas regiões de maior densidade demográfica das cidades da Região Metropolitana ( $r=826$; $\mathrm{p}=0,024)$, encontramos resultados significativos, o que indica uma relação entre o aumento da morbidade policial com maior densidade demográfica. Podemos afirmar, assim como Clarke e $\mathrm{Zak}^{25}$, que as áreas urbanas representam elevada vulnerabilidade para a ocorrência de morbidades por armas de fogo entre policiais e supor que o risco de o policial ser alvejado na cidade do Rio de Janeiro esteja relacionado às áreas de maior concentração de favelas no território.

No que concerne aos batalhões onde estavam lotados os profissionais, destaca-se o maior número de policiais baleados provenientes das UPPs e do BOPE. A despeito da reconhecida 
capacitação tática dos policiais pertencentes ao BOPE, este batalhão apresentou o maior percentual de policiais militares feridos por arma de fogo, considerado o número do efetivo dos batalhões. Este achado questiona a eficácia das recentes políticas públicas adotadas no estado do Rio de Janeiro para redução da vitimização entre os policiais militares ${ }^{26}$. Em linhas gerais, tais políticas públicas foram marcadas por um caráter individualista, voltadas à mudança no estilo de vida do policial, o que remete à perspectiva da culpabilização da vítima. O exemplo mais recente ocorreu após um elevado número de ocorrências de óbitos de policiais militares noticiado pelas mídias, que levou à criação do Programa Permanente de Capacitação Continuada do Policial Militar em janeiro de 2017, cujo objetivo foi reduzir a letalidade por meio de treinamentos específicos que ajudariam o militar a tomar decisões assertivas diante de ameaças ${ }^{27}$. Contudo, a elevada ocorrência de vitimização por armas de fogo encontradas entre os policiais do BOPE expõe a necessidade de mudanças das políticas públicas de segurança baseadas em operações de confronto. Faz-se necessário, com isso, avançar para reformas estruturantes, uma vez que apenas a capacitação tática não é suficiente para produzir a redução da vitimização do policial militar.

Os policiais militares feridos receberam o primeiro atendimento em diversos hospitais na região metropolitana do Rio de Janeiro, em especial na rede SUS localizada na AP 3 da cidade. O HCPM é o hospital que mais recebeu esse tipo de caso.

A mediana do tempo de internação hospitalar no HCPM foi de 0,0 dias, pois grande parte dos pacientes $(50,9 \%)$ foram atendidos no Setor de Pronto Atendimento, em que receberam os cuidados emergenciais para a estabilização do quadro clínico e receberam alta sem serem internados no hospital. Os pacientes que após o atendimento emergencial obtiveram alta do Setor de Pronto Atendimento, mas que precisaram de cirurgias eletivas, retornaram ao hospital e foram internados para a realização do procedimento. A taxa de mortalidade após entrada no hospital pode ser considerada baixa diante do número de pacientes classificados com estado clínico grave e regular $(94,4 \%)$.

Quanto à localização anatômica dos FAF, ressalta-se que os ferimentos em região de tórax -abdome poderiam ser, em boa parte dos casos, evitados ou minimizados através do uso de coletes à prova de balas. Não faz parte do arsenal de equipamentos de proteção individual do po- licial o uso de capacete balístico, contudo, diante do elevado número de ocorrências de ferimentos na região de cabeça-pescoço-face, esse tipo de proteção adicional deveria ser considerado para auxiliar na redução dessas morbidades.

As elevadas taxas de vitimização encontradas entre policiais militares do Rio de Janeiro indicam problemas na estratégia de trabalho e gestão pública que demandam a análise de variados fatores envolvidos. A sociologia clássica, ao analisar a violência nas sociedades ocidentais, entende o Estado como um componente central para a sua compreensão. Como ressaltou Weber ${ }^{28}$, a conformação do Estado Moderno o colocou como detentor do monopólio da violência física, ou o direito à violência, com vistas ao controle social. Wieviorka $^{29}$ pondera que, diante das mudanças no cenário mundial e da dificuldade dos Estados contemporâneos em assumir suas funções clássicas, observam-se sinalizações do declínio desse modelo. A despeito das mudanças ocorridas nas últimas décadas, a Segurança Pública continua a desempenhar um importante papel na ambiência do Estado Democrático de Direito, já que muito mais que a repressão frente a condutas ilegais, é esperado das polícias a distribuição igualitária e isonômica do usufruto dos direitos à liberdade e à propriedade em um grau máximo a todos os indivíduos da coletividade ${ }^{30}$. Ao analisar o cenário de violência contra o policial no Rio de Janeiro, muitos aspectos precisariam ser abordados diante da complexidade do tema, contudo consideraremos duas questões que podemos circunscrever a partir da perspectiva da Saúde Pública. A primeira revela que os elevados números de vitimização de policiais militares apontam para sintomas de desestruturação do sistema de segurança em que a própria vitimização do policial militar, em certa medida, expõe a fragilidade do Estado. A segunda revela que é crucial que haja uma mudança na compreensão do policial militar como um trabalhador e sujeito de direitos, e de que a falta de informação em saúde destes produz um obscurecimento sobre esta classe profissional enquanto trabalhadores.

Minayo, Souza e Constantino ${ }^{21}$ definiram a PMERJ como uma corporação hierarquicamente organizada e disciplinada que possui uma vida institucional rica em mitos, símbolos, insígnias e intensidade de visão corporativa. A profissão é regida pelo Estatuto dos Policiais Militares do Estado do Rio de Janeiro, Lei no 443 de $1^{\circ}$ de julho de $1981^{31}$, que regula a situação, obrigações, deveres, direitos e prerrogativas destes policiais. Dentre os mitos e símbolos nutridos, podemos 
perceber, a partir de seu Estatuto, que a relação de trabalho do policial é simbolicamente encarada como missão sacerdotal. No seu artigo 26, entre os itens de manifestações essenciais do valor e dever do policial, está o "integral devotamento à manutenção da ordem pública, mesmo com o risco da própria vida" 31 . Ainda no Estatuto da PMERJ, no capítulo II, exige-se a dedicação integral ao serviço policial-militar, o que já coloca em questão se de fato o policial, em algum momento, está de folga do serviço, já que deve estar integralmente dedicado e disposto, inclusive, a sacrificar a própria vida. Percebe-se aí, talvez, uma das raízes da naturalização da vitimização do policial, uma vez que é considerado como dever que o policial arrisque sua própria vida e que seu corpo sofra o martírio em favor de um suposto bem maior.

As consequências dessa forma de ser policial são, na prática, as altas taxas de morbimortalidade. Da mesma sorte, quando não publicizamos essas marcas nos corpos em decorrência da violência, ao longo do tempo, contribuímos com seu apagamento, que, em si, tem uma intenção política. A falta de divulgação das morbidades por lesões por arma de fogo entre os policiais militares, um símbolo da violência armada, especialmente no Rio de Janeiro, pode apontar para as intencionalidades de discursos que naturalizam a violência sobre o corpo do policial. Segundo Foucault $^{32}$, a verdade não existe fora da relação de poder e opera através de uma economia política construída a partir de cinco características: nasce a partir do discurso científico, está vinculada a um interesse econômico e político e é reproduzida, difundida e consumida extensamente pelo corpo social. A divulgação dessas verdades, na forma de discursos, está sob o controle dominante de grandes aparelhos político-econômicos: elas estão em disputa e são constantemente confrontadas e submetidas a lutas pretensamente ideológicas. Nesse cenário de produção ou interrupção de discursos, identificamos, na ausência de informações sobre as morbidades por arma de fogo entre policiais militares em virtude da violência, uma intenção de interrupção de um discurso que confronta o saber hegemônico que considera o policial um profissional com vocação sacerdotal ou heroica e que naturaliza a violência. Contudo, esses discursos e saberes estão sujeitos à emergência, à entrada de outras forças que tencionam a verdade, podendo reafirmá-la ou transmutá-la. As diretorias de saúde e seus profissionais na PMERJ podem ser, portanto, lugares de emergência, de afrontamento e luta, em virtude inclusive de sua natureza, a saber, a responsabilidade de zelar pela saúde do policial. Mesmo não sendo o único responsável por essa emergência, o campus da saúde na PMERJ pode desempenhar um papel importante no realinhamento do discurso atual, o que representa um potente ator nesse cenário de forças em disputa.

As Diretorias de Saúde da PMERJ constituem um elemento-chave para a colaboração na construção de um saber que coloque em suspensão a naturalização da violência contra os corpos dos policiais. Além disso, a visibilização de informações relativas às morbidades de policiais auxiliará na construção de análises e diagnósticos mais complexos sobre os fatores envolvidos na violência do policial, na sua forma de atuação e planejamento estratégico. Tais elementos podem tornar mais robustas as políticas públicas de saúde para o policial e de segurança para o Estado, a fim de que se alcançar ambiente propício para o desenvolvimento e para a democracia.

$\mathrm{O}$ artigo possui limitações, como não contar com uma amostra representativa do total de policiais militares acometidos por FAF na cidade do Rio de Janeiro, já que existem policiais militares que podem ter sido atendidos, em caráter de urgência, em hospitais da rede privada ou em outros hospitais públicos e podem não ter sido transferidos para o HCPM, o que indica que o quadro apresentado pode ser ainda mais grave. Além dos motivos descritos, em virtude da gravidade dos acidentes e a distância do local da ocorrência desses ferimentos até o HCPM, alguns policiais são encaminhados de forma primária às unidades de pronto-atendimento da rede do SUS mais próximas e, após estabilização do quadro clínico, por vezes são transferidos para o HCPM. Não podemos, contudo, dizer que todos os policiais militares do Rio de Janeiro são atendidos apenas por essa unidade de saúde, já que a adesão ao plano de saúde da PM é opcional, havendo a possibilidade de outros militares serem atendidos pela rede privada ou apenas pela rede do SUS. Também não foram analisados neste estudo os casos fatais de policiais militares acometidos por FAF.

Apesar dessas limitações, os dados apresentados apontam para um problema de saúde relevante para esta categoria profissional, para a qual não há qualquer informação de magnitude e extensão; tampouco existe o monitoramento desse tipo de ocorrência entre os policiais que são atendidos fora do HCPM, o que indica a necessidade de que seja criado um sistema monitorador das morbidades ocorridas entre esses trabalhadores 
no país e aponta para os profissionais de saúde como elementos-chave para a formação desses sistemas de informação em saúde.

\section{Conclusão}

Os resultados deste estudo apontam para alta ocorrência de morbidade por arma de fogo entre os policiais militares no Rio de Janeiro. O perfil desses policiais indica uma maior vulnerabilidade entre os praças, do sexo masculino, feridos em serviço. Constatou-se correlação entre as taxas de morbidade policial por armas de fogo dos municípios da Região Metropolitana e densidade demográfica. A identificação dos fatores de risco e as circunstâncias envolvidas nesse tipo de agravo à saúde desses profissionais podem ajudar na elaboração de recomendações e políticas de prevenção desse tipo de morbidade.

\section{Colaboradores}

ABP Maia participou da concepção, planejamento, análise, interpretação e redação do trabalho; SG Assis, FML Ribeiro e L Wernersbach participaram no planejamento, análise e interpretação do trabalho. Todas as autoras aprovaram a versão final encaminhada. 


\section{Referências}

1. Matta R. As raízes da violência no Brasil: reflexões de um antropólogo social. São Paulo: P.S. Pinheiro; 1982. p.12-43.

2. Waiselfiz JJ. Mapa da violência 2016: homicídios de armas de fogo no Brasil. Rio de Janeiro: FLACSO; 2016.

3. Waiselfiz JJ. Mapa da violência 2013: mortes matadas por armas de fogo. Rio de Janeiro: FLACSO; 2013.

4. Cerqueira D, Lima RSD, Bueno S, Valencia LI, Hanashiro O, Machado PHG, Lima ADS. Atlas da violência 2017. Brasília: IPEA; 2017.

5. Phebo L. Impacto da arma de fogo na saúde da população no Brasil. In: Brasil: as armas e as vítimas. Rio de Janeiro: 7 Letras; 2005. [acessado 2019 fev 12]. Disponível em: http://comunidadesegura.org.br/files/active /0/vitimas_armas_impacto_saude.pdf

6. Fórum Brasileiro de Segurança Pública. Anuário Brasileiro de Segurança Pública 2016 [internet] ano 10; 2016 [acessado 2017 ago 4]. Disponível em: http:// www.forumseguranca.org.br/storage/10_anuario_site_18-11-2016-retificado.pdf.

7. Ehikhamenor EE, Ojo MA. Comparative analysis of traumatic deaths in Nigeria. Prehosp Disaster Med 2005; 20(3):197-201.

8. Maia ABP. Vitimização policial: morbidade por arma de fogo de policiais militares do estado do Rio de Janeiro. [dissertação]. Rio de Janeiro: Fundação Oswaldo Cruz; 2018.

9. Brasil. Ministério da Saúde (MS). Secretaria de Vigilância em Saúde, Departamento de Vigilância de Doenças e Agravos Não Transmissíveis e Promoção da Saúde. Viva: Vigilância de Violências e Acidentes: 2013 e 2014 [internet]. Brasília: MS; 2017 [acessado 2017 ago 2]. Disponível em: http://bvsms.saude.gov. br/bvs/publica coes/viva_vigilancia_violencia_acidentes_2013_2014.pdf

10. Rede Interagencial de Informação para a Saúde (RIPSA). Indicadores básicos para a saúde no Brasil: conceitos e aplicações. 2. ed. Brasília: Organização Pan-Americana da Saúde; 2008.

11. Souza ER, Njaine K, Minayo MCS. A qualidade da informação sobre violência: um caminho para a construção da cidadania. Cadernos do Programa de Pósgraduação em Ciência da Informação 1996; 2(1):104112.

12. Instituto de Segurança Pública do Rio de Janeiro (ISPRJ). Relatório Vitimização Policial: 1998 - nov 2015 [eletrônico]. Rio de Janeiro: ISPRJ; 2015 [acessado 2017 ago 4]. Disponível em: http://arquivos.proderj. rj.gov.br/ispimagens/uploads/RelatorioVitimizacao2015.pdf

13. Programa das Nações Unidas para o Desenvolvimento (PNUD). Relatório do Desenvolvimento Humano 2014. Nova Iorque: PNUD; 2014. [acessado $2019 \mathrm{mar}$ 13]. Disponível em: https://www.undp.org/content/ dam/brazil/docs/RelatoriosDesenvolvimento/undp -br-hdr_portugues-2014.pdf

14. Instituto Brasileiro de Geografia e Estatística (IBGE). Censo Demográfico 2010: Aglomerados subnormais, primeiros resultados. Brasília: IBGE; 2011. [acessado 2019 mar 13]. Disponível em: https://biblioteca.ibge. gov.br/visualizacao/periodicos/92/cd_2010_aglomerados_subnormais.pdf
15. Plani F, Bowley DM, Goosen J. Death and injury on duty-a study of South African police officers. South African Medical J 2003; 93(11):851-853.

16. Federal Bureau of Investigation. Law Enforcement Officers Killed and Assaulted. Type of Weapon and Percent Injured, 2007-2016 [internet]. [acessado 2017 ago 20]. Disponível em: https://ucr.fbi.gov/leoka/2016/ officers-assaulted/tables/table-75.xls.

17. Berman AT, Salter F. Low-velocity gunshot wounds in police officers. Clinical Orthop Relat Res 1985; (192):113-119.

18. Muniz J, Soares BM, organizadores. Mapeamento da vitimização de policiais no Rio de Janeiro. Rio de Janeiro: Centro de Estudos de Segurança e Cidadania; 1998. [acessado 2018 nov 5]. Disponível em: https://www. ucamcesec.com.br/wp-content/uploads/2011/05/ Monitoramento_vitimizacao_policiais.pdf

19. Souza ER, Minayo MCS. Policial, risco como profissão: morbimortalidade vinculada ao trabalho. Cienc Saude Colet 2005; 10(4):917-928.

20. Minayo MSC, Souza ER, Constantino P. Riscos percebidos e vitimização de policiais civis e militares na (in) segurança pública. Cad Saude Publica 2007; 23(11):2767-2779.

21. Minayo MCS, Souza ERD, Constantino P. Missão prevenir e proteger: condições de vida, trabalho e saúde dos policiais militares do Rio de Janeiro: Editora Fiocruz; 2008.

22. Minayo MCS, Assis SG, Vasconcellos COR. Impacto das atividades profissionais na saúde física e mental dos policiais civis e militares do Rio de Janeiro. Cienc Saude Colet 2011; 16(4):2199-2209.

23. Swedler DI, Kercher C, Simmons MM, Pollack KM. Occupational homicide of law enforcement officers in the US, 1996-2010. Inj Prev 2013; 20(10):35-40.

24. Kyriacou DN, Monkkonen EH, Peek-Asa C, Lucke RE, Labbett S, Pearlman KS, Hutson HR. Police deaths in New York and London during the twentieth century. Inj Prev 2006; 12(4):219-224.

25. Clarke C, Zak MJ. Fatalities to law enforcement officers and firefighters, 1992-1997. Month Labor Review 1999; 3-7.

26. Ramos S. Violência e polícia: três décadas de políticas de segurança no Rio de Janeiro. Bol Segur Cidadania 2016; 21: 1-33.

27. Polícia Militar do Estado do Rio de Janeiro (PMERJ). Programa Permanente de Capacitação Continuada [internet]; 2017 jan 5. Rio de Janeiro: PMERJ; 2017 [acessado 2017 ago 4]. Disponível em: https://pmerj. rj.gov.br/nota-sobre-vitimizacao-de-policiaismilitares/.5dejande2017

28. Weber M. Economia e sociedade: fundamentos da sociologia compreensiva. $4^{\text {a }}$ ed. Brasília: Universidade de Brasília; 2004.

29. Wieviorka M. The new paradigm of violence. Tempo social 1997; 9(1):5-41.

30. Andrade Filho ACB. O poder de polícia no estado democrático de direito. Rev Jus Navigandi 2009; 14:(2138) [acessado 2018 mar 18]. Disponível em: https://jus.com.br/artigos/12771/o-poder-de-policiano-estado-democrati co-de-direito 
31. Brasil. Lei ${ }^{\circ} 443$ de 1 de julho de 1981. Estatuto dos Policiais Militares do Estado do Rio de Janeiro. Diário Oficial da União 1981; 02 jul.

32. Foucault M. Microfísica do poder. $4^{\mathrm{a}}$ ed. Rio de Janeiro: Paz \& Terra; 2016.

Artigo apresentado em 30/04/2019

Aprovado em 18/07/2019

Versão final apresentada em 20/07/2019

Editores-chefes: Romeu Gomes, Antônio Augusto Moura da Silva 